\title{
How shall we treat pregnant women infected with 2019-nCoV?
}

\author{
Valentine Bardon ${ }^{1}$, Laurent Salomon ${ }^{2}$, Marianne Ville $^{3}$, and Yves Ville ${ }^{3}$ \\ ${ }^{1}$ Hôpital universitaire Necker-Enfants malades \\ ${ }^{2} \mathrm{CHU}$ NECKER \\ ${ }^{3}$ Affiliation not available
}

April 28, 2020

Specific therapies in pregnant women are discussed

The health crisis caused by the novel SARS-cov-2 (2019-nCoV) related pandemic requires urgent and necessary therapeutic response. Pregnant women are just as exposed as the general population and should not be excluded, because of their status, from discussions on effective and well tolerated candidate treatments. While in countries that have opted for national containment, daily non-emergency medical and surgical activities are suspended, obstetric services continue to operate relentlessly and are experiencing a surge in so-called "at-risk" pregnancies. Some countries have now recommended routine screening of all pregnant women ${ }^{1}$ but the low availability and performance of the current tests limits their use. Management of an infected pregnant women is essentially conditioned by maternal symptomatology. Women with little or no symptoms do not require routine treatment or in-patient care and simply need to be monitored for up to 15 days for evidence of respiratory deterioration. In the absence of validated specific treatment, the primary approach to therapy is mainly symptomatic and delivery is considered in the event of critical respiratory distress in order to maximize oxygenation and lung capacity ${ }^{2-4}$. However, it has been reported that women with respiratory signs may be given antiviral treatment to improve their clinical condition ${ }^{2,4}$

To date, there is no proven effective strategy, although many teams are working tirelessly to identify an effective treatment. Four molecules are leading in this race:

1) Remdesivir is a novel nucleotide analogue prodrug which incorporates into nascent viral RNA chains and results in pre-mature termination. Its effectiveness has been already demonstrated against others coronaviruses such as SARS-Cov and MERS-Cov ${ }^{5}$, and it has proven to be highly effective on in vitro 2019-nCoV infection ${ }^{6}$. Compassionate use in human were also reported ${ }^{7}$ and phase 3 studies are currently underway.

2) (Hydroxy)chloroquine has been known for years because of its effectiveness in the treatment of inflammatory diseases and against malaria. Recent studies have shown antiviral effects of chloroquine and in vitro studies concluded that it was highly effective in the control of $2019-\mathrm{nCoV}^{6,8}$. Elevation of endosomal $\mathrm{pH}$ and interference with terminal glycosylation of the cellular receptor, angiotensin-converting enzyme 2 conduct to block virus infection. (Hydroxy)chloroquine has been used in 2019-nCoV infected humans with highly controversial restuls $^{9,10}$ and well-designed randomized studies should be available soon.

3) Lopinavir, a viral protease inhibitor, with its pharmacological booster Ritonavir (LPV/R) are commonly used in HIV positive patients. It has already been used for SARS-Cov. Some countries such as China and India approved its use in symptomatic infected patients although a first randomized, controlled, open-label trial showed no benefit of LPV/R over standard care in patients with severe $2019-\mathrm{nCoV}$ disease ${ }^{11}$.

4) Ribavirin, is a guanosine analog that interferes with the replication of RNA and DNA viruses. It has been used for years in the treatment of chronic hepatitis C. Based on its direct anti-viral activity against 2019-nCoV in vitro and some evidence for its potential efficacity during the prior SARS-Cov and MERS-Cov 
outbreaks, it has been suggested as a potential candidate for the treatment of $2019-\mathrm{nCoV}$ diease ${ }^{12}$. 2019$\mathrm{nCoV}$ infected patients treated with Ribavirin have been reported by Chinese studies ${ }^{4,13}$ but its exact benefit remains to be demonstrated in well designed randomized studies as well.

To date, all four drugs are being independently tested in Phase 3 studies, mostly national, to investigate their efficacy and safety in the management of 2019-nCoV disease. Several European countries have also set up, as a result of joint efforts since mid-March, a randomized, multicentre, open-label trial to evaluate and compare the efficacy and toxicity of the first three treatments mentioned above. ${ }^{14}$

With regard to the possibility of treating pregnant patients with these molecules, few data are available for Remdesivir. Only one study reports its use in six pregnant women in a randomized trial during Ebola epidemics. The authors reported no adverse effect ${ }^{15}$.

Many more pharmacological studies on maternal-fetal tolerance of Hydroxy(chloroquine), Lopinavir and Ribavirin are available. The historical use of (hydroxy)chloroquine in antimalarial treatment, but also in connective tissue diseases, has resulted in a well-documented safety and tolerance profile in pregnant women ${ }^{16}$. Animal studies, undertaken during the Zika virus epidemic, have also suggested that chloroquine may also reduce the risk of viral transplacental transmission to the fetus ${ }^{17}$. The optimal dosage to be used in pregnant women will have to be specified, but it appears that there is no pharmacokinetic difference between chloroquine and its major metabolite between pregnant and non-pregnant women ${ }^{18}$. With respect to the use of protease inhibitors during pregnancy, such as Lopinavir, some teams have reported an increased risk of preterm delivery. However, a specific analysis of more than 4,000 pregnant women found a similar incidence and rate of adverse pregnancy outcomes than in controls at all three trimesters of pregnancy, including preterm birth, low birth weight and birth defects ${ }^{19}$. Significant teratogenic effects have been demonstrated in all animal species exposed to Ribavirin, it is therefore currently contraindicated in pregnant women and in their male sexual partners, although the ribavirin pregnancy registry did not bring evidence of teratogenicity in humans ${ }^{20}$.

The use of antiviral therapy in infected pregnant patients should follow the same indication as in the general population, but some obstetric specificities should be emphasized.

1) The main goal should be to slow down and at best stop the clinical progression of the disease, i.e to remain asymptomatic and to avoid progression to acute respiratory distress syndrome in symptomatic cases. In the latter, the obstetrician is often called on to perform an emergency delivery and thus to induce extreme prematurity. Expert consensus provided obstetric guidance, but the management of cases at between 25 and 32 weeks' remains challenging in the absence of effective antiviral treatment ${ }^{1}$.

2) The second objective would be to rapidly decrease viral load and duration of contagiousness in infected pregnant women. The majority of them are doing well, but the infection can disrupt their obstetrical calendar. Some procedures need to be performed at a specific age, such as first trimester serum markers, ultrasound examinations, chorionic villi sampling (CVS). The same applies to access to termination of pregnancy. All such procedures may indeed be delayed, either to limit contagion, to limit the burden on the health care team (due to reinforced barrier measures...) or in the particular case of CVS/amniocentesis, to limit the theoretical risk of fetal transmission.

3) Finally, the third advantage could be to introduce preventive treatment in case of maternal contact with an infected person, similar to what is done for seasonal influenza and oseltamivir ${ }^{21}$.

The use of immunotherapy such as Tocilizumab, plasma of recovered coronavirus patient, Interferons, were not discussed here as they are currently understudy only for critically ill COVID-19 patients. No place for these treatments in a patient who is still pregnant should be considered for the time being, since if the pregnant woman presents a very severe form, the birth will be considered as a priority.

The results of the Phase 3 therapeutic studies should be available soon. However, it is unfortunate that infected pregnant women are not included in any appropriate research protocols. Consequently, in this period 
of pandemic, mutual exchanges of experience between all countries' maternity hospitals must be carried out in order to ensure the best possible management of infected pregnant women.

\section{References}

1. Peyronnet V, Sibiude J, Deruelle P, Huissoud C, Lescure X, Lucet J-C, et al. Infection par le SARSCoV-2 chez les femmes enceintes. État des connaissances et proposition de prise en charge. CNGOF. Gynécologie Obstétrique Fertil Sénologie [Internet]. 2020 Mar 19 [cited 2020 Mar 30]; Available from: http://www.sciencedirect.com/science/article/pii/S2468718920301100

2. Chen H, Guo J, Wang C, Luo F, Yu X, Zhang W, et al. Clinical characteristics and intrauterine vertical transmission potential of COVID-19 infection in nine pregnant women: a retrospective review of medical records. The Lancet [Internet]. 2020 Mar 7 [cited 2020 Apr 2];395(10226):809-15. Available from: http://www.sciencedirect.com/science/article/pii/S0140673620303603

3. Safe Delivery for COVID-19 Infected Pregnancies - Qi - - BJOG: An International Journal of Obstetrics \&amp; Gynaecology - Wiley Online Library [Internet]. [cited 2020 Apr 2]. Available from: https://obgynonlinelibrary-wiley-com.sirius.parisdescartes.fr/doi/abs/10.1111/1471-0528.16231

4. Yu N, Li W, Kang Q, Xiong Z, Wang S, Lin X, et al. Clinical features and obstetric and neonatal outcomes of pregnant patients with COVID-19 in Wuhan, China: a retrospective, single-centre, descriptive study. Lancet Infect Dis [Internet]. 2020 Mar 24 [cited 2020 Mar 30]; Available from: http://www.sciencedirect.com/science/article/p

5. Sheahan TP, Sims AC, Graham RL, Menachery VD, Gralinski LE, Case JB, et al. Broad-spectrum antiviral GS-5734 inhibits both epidemic and zoonotic coronaviruses. Sci Transl Med [Internet]. 2017 Jun 28 [cited 2020 Apr 1];9(396). Available from: https://stm-sciencemag-org.sirius.parisdescartes.fr/content/9/396/eaal3653

6. Wang M, Cao R, Zhang L, Yang X, Liu J, Xu M, et al. Remdesivir and chloroquine effectively inhibit the recently emerged novel coronavirus (2019-nCoV) in vitro. Cell Res [Internet]. 2020 Mar [cited 2020 Apr 1];30(3):269-71. Available from: http://www.nature.com/articles/s41422-020-0282-0

7. Holshue ML, DeBolt C, Lindquist S, Lofy KH, Wiesman J, Bruce H, et al. First Case of 2019 Novel Coronavirus in the United States. N Engl J Med [Internet]. 2020 Mar 5 [cited 2020 Apr 1];382(10):929-36. Available from: https://doi.org/10.1056/NEJMoa2001191

8. Yao X, Ye F, Zhang M, Cui C, Huang B, Niu P, et al. In Vitro Antiviral Activity and Projection of Optimized Dosing Design of Hydroxychloroquine for the Treatment of Severe Acute Respiratory Syndrome Coronavirus 2 (SARS-CoV-2). Clin Infect Dis [Internet]. [cited 2020 Apr 1]; Available from: https://academicoup-com.sirius.parisdescartes.fr/cid/advance-article/doi/10.1093/cid/ciaa237/5801998

9. Colson P, Rolain J-M, Raoult D. Chloroquine for the 2019 novel coronavirus SARS-CoV-2. Int J Antimicrob Agents [Internet]. 2020 Mar 1 [cited 2020 Apr 1];55(3):105923. Available from: http://www.sciencedirect.com/science/ar

10. CHEN Jun LD, CHEN Jun LD. A pilot study of hydroxychloroquine in treatment of patients with common coronavirus disease-19 (COVID-19). J Zhejiang Univ Med Sci [Internet]. 2020 Mar 6 [cited 2020 Apr 1];49(1):0-0. Available from: http://www.zjujournals.com/med/EN/abstract/abstract41137.shtml

11. Cao B, Wang Y, Wen D, Liu W, Wang J, Fan G, et al. A Trial of Lopinavir-Ritonavir in Adults Hospitalized with Severe Covid-19. N Engl J Med [Internet]. 2020 Mar 18 [cited 2020 Apr 1]; Available from: https://doi.org/10.1056/NEJMoa2001282

12. Khalili JS, Zhu H, Mak A, Yan Y, Zhu Y. Novel coronavirus treatment with ribavirin: Groundwork for evaluation concerning COVID-19. J Med Virol [Internet]. [cited 2020 Apr 1];n/a(n/a). Available from: http://onlinelibrary.wiley.com/doi/abs/10.1002/jmv.25798 
13. Wu J, Li W, Shi X, Chen Z, Jiang B, Liu J, et al. Early antiviral treatment contributes to alleviate the severity and improve the prognosis of patients with novel coronavirus disease (COVID-19). J Intern Med [Internet]. [cited 2020 Mar 29];n/a(n/a). Available from: http://onlinelibrary.wiley.com/doi/abs/10.1111/joim.13063

14. Trial of Treatments for COVID-19 in Hospitalized Adults - Full Text View - ClinicalTrials.gov [Internet]. [cited 2020 Apr 1]. Available from: https://clinicaltrials.gov/ct2/show/NCT04315948

15. Mulangu S, Dodd LE, Davey RT, Tshiani Mbaya O, Proschan M, Mukadi D, et al. A Randomized, Controlled Trial of Ebola Virus Disease Therapeutics. N Engl J Med [Internet]. 2019 Dec 12 [cited 2020 Apr 2];381(24):2293-303. Available from: https://doi.org/10.1056/NEJMoa1910993

16. Hydroxychloroquine (HCQ) in lupus pregnancy: double-blind and placebo-controlled study - R A Levy, V S Vilela, M J Cataldo, R C Ramos, J LMB Duarte, B R Tura, E MN Albuquerque, N R Jesus, 2001 [Internet]. [cited 2020 Apr 2]. Available from: https://journals-sagepub-com.sirius.parisdescartes.fr/doi/abs/10.1191/0961203016786461

17. Zhang S, Yi C, Li C, Zhang F, Peng J, Wang Q, et al. Chloroquine inhibits endosomal viral RNA release and autophagy-dependent viral replication and effectively prevents maternal to fetal transmission of Zika virus. Antiviral Res [Internet]. 2019 Sep 1 [cited 2020 Apr 2];169:104547. Available from: http://www.sciencedirect.com/scien

18. Lee SJ, McGready R, Fernandez C, Stepniewska K, Paw MK, Viladpai-nguen SJ, et al. Chloroquine pharmacokinetics in pregnant and nonpregnant women with vivax malaria. Eur J Clin Pharmacol [Internet]. 2008 Jul 2;64(10):987. Available from: https://doi.org/10.1007/s00228-008-0500-z

19. Tookey PA, Thorne C, Wyk J van, Norton M. Maternal and foetal outcomes among 4118 women with HIV infection treated with lopinavir/ritonavir during pregnancy: analysis of population-based surveillance data from the national study of HIV in pregnancy and childhood in the United Kingdom and Ireland. BMC Infect Dis [Internet]. 2015 Dec [cited 2020 Apr 2];16(1):1-11. Available from: https://bmcinfectdisbiomedcentral-com.sirius.parisdescartes.fr/articles/10.1186/s12879-016-1400-y

20. The Ribavirin Pregnancy Registry: An Interim Analysis of Potential Teratogenicity at the Mid-Point of Enrollment. - PubMed - NCBI [Internet]. [cited 2020 Apr 2]. Available from: https://www-ncbi-nlm-nihgov.sirius.parisdescartes.fr/pubmed/28689333

21. ACOG Committee Opinion No. 753: Assessment and Treatment of Pregnant Women With Suspected or Confirmed Influenza. Obstet Gynecol [Internet]. 2018 Oct [cited 2020 Apr 4];132(4). Available from: insights.ovid.com 